\title{
Methodological Approach for Identification of Organic Residues Preserved in Roman Amphorae
}

\begin{abstract}
Charlotte Saint-Raymond ${ }^{1}$, Camille Frugier ${ }^{1,2}$, Nadia Cantin ${ }^{1}$, Florence Verdin ${ }^{3}$, Camille Noûs ${ }^{4}$, Séverine Lemaître ${ }^{2}$, Christelle Absalon ${ }^{5}$ and Isabelle Pianet ${ }^{1 *}$
\end{abstract}

${ }^{1}$ IRAMAT-CRP2A, UMR 5060, Bordeaux Montaigne University, France

${ }^{2}$ HERMA, EA 3811, University of Poitiers, Hotel Fumé, France

${ }^{3}$ Ausonius, UMR 5607, Bordeaux Montaigne University, France

${ }^{4}$ Cogitamus Laboratory, France

${ }^{5}$ Cesamo-ISM, UMR 5255, University of Bordeaux, France

ISSN: 2637-8078

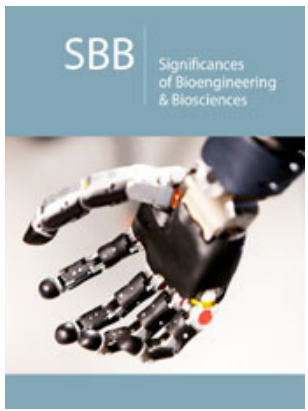

*Corresponding author: Isabelle Pianet, IRAMAT-CRP2A, UMR 5060, Bordeaux Montaigne University, CNRS, House of Archeology, Esplanade des Antilles, 33600 Pessac, France

Submission: 漹 January 8, 2021

Published: 监January 28, 2021

Volume 4 - Issue 4

How to cite this article: Charlotte SaintRaymond, Camille Frugier Nadia Cantin, Isabelle Pianet, et al. Methodological Approach for Identification of Organic Residues Preserved in Roman Amphorae. Significances of Bioengineering \& Biosciences .4(4). SBB. 000591. 2021. DOI: 10.31031/SBB.2021.04.000591

Copyright@ Isabelle Pianet, This article is distributed under the terms of the Creative Commons Attribution 4.0 International License, which permits unrestricted use and redistribution provided that the original author and source are credited.

\begin{abstract}
Several studies have focused on local workshops in the Picton territory, the western center of Gaul. Picton potters notably reproduced the forms of amphorae imported from the north of Spain (Pascual 1, Dressel 2/4), or from the Narbonensis province (Gauloise 4 and 5). To ascertain to what end these amphorae were manufactured in the region, the chemical study of the organic residues left in the vessels was undertaken. An analytical protocol with a two-step analysis is proposed herein. Firstly, py-GCMS of sherds gives rise to a global print of the different compounds present in their pores, and permits to choose an adapted protocol of extraction for further GCMS analysis. In the present work, the methodology is tested using amphorae sherds originating from local workshops-hence never used-that we soaked in a wine of known composition, before analyzing them via both GCMS and py-GCMS showing the complementary of these approaches and their efficiency in the study of archaeological organic residues originating from amphorae found in consumption sites in Poitiers.
\end{abstract}

Keywords: Organic residues; Roman amphorae; Human handling; Burial; Phenolic carboxylic acids Resins; Low volatility; Malic; Syringic

\section{Introduction}

The chemical analysis of residues absorbed in the ceramic pores or even sometimes deposits in vessels generally permits to ascribe the object to its function. However, the difficulty lies in selecting the most suitable/appropriate strategy since the chemical nature of the constitutive compounds of the residue is not known. The solvent/solvent mixture used for the extraction requires a minima some hypothesis concerning the chemical nature of what must be identified, beyond all other potential interference (washing, human handling, burial, degradation, conservation treatment, pollutants...). Typically, the chemical analysis performed on artefacts consists of testing the presence or absence of predetermined compounds. Even if precautions should be taken, notably to ensure the primacy of contextual information of the artefacts to be analyzed [1,2], this approach is restrictive since "absence of evidence is not evidence of absence". This is the example of tartaric acid, whose presence is systematically checked to prove the presence of wine/grape in a recipient, and numerous tailor-made analytical protocols were proposed for more than 25 years such as FT-IR spectroscopy, GC-MS and LC MS using different extraction procedures [3-8]. However, its absence is inconclusive since its longevity is not ensured due to its water solubility. Fortunately, the detection of alternative compounds can also reveal the presence of wine, such as other organic acids, phenolic carboxylic acids, which are degradation products of polyphenols [9] and give information on the grape/wine colour, as polyphenols are present in larger amounts in red grapes than in their white counterparts [10] or even resins, which gives information on the way that ancient populations preserved their wine and/or gave a special taste and/or waterproofed the recipient.

The quest of unknown biomarkers requires an analytical approach susceptible to give a general survey of the molecules present, without any previous discriminant protocol such as 
extraction. In order to satisfy this objective, pyrolysis, a technique developed in the 1960s was implemented. It offers the possibility to analyze organic macromolecules of low volatility. Another asset of pyrolysis lays in the fact that the extraction step inherent to GCMS-restrictive due to the compelled selection of an extraction solvent- becomes unnecessary. For this purpose, the method was first improved with sherds impregnated with model solution and with wine before being applied to an archaeological sample.

\section{Materials and Methods}

\section{Materials}

Apparatus: GC-MS analyses (CESAMO facilities) were performed on a mass spectrometer hyphenated with a chromatograph Trace GC Ultra equipped with a GC column $15 \mathrm{~m}$ long, $0.25 \mathrm{~mm}$ diameter and $0.25 \mu \mathrm{m}$ film thickness (Thermo Scientific TM). Data were acquired and processed using the internal software of Thermo Scientific TM, Xcalibur. Pyrolyses were carried out with a Pyrolyzer PY-3030S from Frontier Lab. Spectra were identified by comparing with spectra of the NIST database.

Chemicals: VWR chemicals provides potassium hydroxide ( $\mathrm{KOH})$, hydrochloric acid $(\mathrm{HCl}, 37 \%)$ acetonitrile and ethyl acetate; Sigma-Aldrich provided malic, syringic and p-coumaric acids and tetramethyl ammonium hydroxide (TMAH) methanol solution (25\%); Acros Organics provided tartaric and citric acids. Supelco Analytical provides the N, O-bis(trimethylsilyl) trifluoroacetamide/ trimethylchlorosilane mixture (BSTFA:TMCS, 99:1). The wine used for imbibition was the Mulsum purchased at "Mas des Tourelles", a wine prepared using a recipe of Columell.

Sherd samples: Two different ceramics were used as model samples: a home-made one [1], and a sherd of a Dressel 2/4 amphora [2] from the archaeological site of Gourgé [11] known as a production workshop [12]. This late sample was chosen as a model since it probably never contained any wine or resin due to its provenance. A residue collected from an amphora [3] found in a well on the hill fort of the Ermitage in Agen [13] (Table 1).

Table 1: Samples analyzed

\begin{tabular}{|c|c|c|c|}
\hline Sample & Sample $\mathbf{N}^{\circ}$ & Material & Kind of Sample \\
\hline Home-Made sherd & 1 & Ceramic & Experimental \\
\hline Amphora & 2 & Ceramic & Archaeological Workshop Gourgé \\
\hline Amphora & 3 & Archaeological Well $\mathrm{n}^{\circ} 41.296$ Hillfort Ermitage from Dressel 1A \\
\hline
\end{tabular}

\section{Methods}

Imbibition: The imbibition protocol was implemented as previously described in [6]. Each ceramic sherd was split between an imbibed sample and its control (1-C and 2-C). Samples were then thoroughly cleaned with distilled water, dried in an oven at $100{ }^{\circ} \mathrm{C}$ for 24 hours and weighed (1-C and 2-C) or immersed in solution A (1-A and 2-A) or in wine (1-W and 2-W) for 3 days. Solution A was made of a concentration of $2 \mathrm{~g} / \mathrm{L}$ of syringic, tartaric, citric, $\mathrm{p}$-coumaric and fumaric acid in an ethanol: water solution (10\% ethanol) and the $\mathrm{pH}$ were adjusted for the dissolution of the different acids.

Extraction: The extraction was performed as described by Pecci and her collaborators [6]. $1 \mathrm{~g}$ of each sample reduced in powder was extracted with $3 \mathrm{~mL}$ of a $1 \mathrm{M} \mathrm{KOH}$ solution and sonicated for $90 \mathrm{~min}$. The supernatant collected after centrifugation $(20 \mathrm{~min}$. at 2000rpm) was adjusted to $\mathrm{pH} 2$ with a $\mathrm{HCl}$ solution before adding $3 \mathrm{~mL}$ of ethyl acetate. After shaking, the organic phase was collected and dried with anhydrous sodium sulfate to remove any trace of water. The procedure was repeated 2 times and all the previously dried organic phases were combined and evaporated under a nitrogen flow until obtaining a dry extract.

GC-MS analysis: Before the GC-MS analysis, the extracts were silylated as follow: $100 \mu \mathrm{L}$ of an N, O-Bis (trimethylsilyl) trifluoroacetamide/trimethylchlorosilane (BSTFA/TMCS; 99:1) mixture and $100 \mu \mathrm{L}$ of acetonitrile were added to the dry extract. The samples were then left for 1 hour at $70{ }^{\circ} \mathrm{C}$ for the silylation reaction to take place. $1 \mu \mathrm{L}$ of each sample was injected for analysis and the carri- er helium flow rate was set at $1.2 \mathrm{~mL} / \mathrm{min}$. The injector was programmed to operate in splitless mode and the analysis of the compounds obtained after separation was carried out using the electron ionization mode $(70 \mathrm{eV})$ over a detection range of $36-800 \mathrm{~m} / \mathrm{z}$.

Pyrolysis GC-MS analysis: $5 \mu \mathrm{L}$ of tetramethylammonium hydroxide (TMAH) were added to approx. $2 \mathrm{mg}$ of each sample, then left for a few minutes at $70^{\circ} \mathrm{C}$ so that the derivatization of the compounds took place and heated for a few seconds until complete evaporation of the solvent, using the thermally assisted hydrolysis and methylation protocol developed by Challinor [14]. The samples were then analyzed by Pyrolysis-GC-MS. As previously, the injector was programmed to operate in split mode at $500{ }^{\circ} \mathrm{C}$ and the analysis of the compounds obtained after separation was carried out using the electron ionization mode $(70 \mathrm{eV})$ over a detection range of 36$800 \mathrm{~m} / \mathrm{z}$.

Identification of the compounds: The compounds were identified by comparing their mass spectrum to the NIST libraries with respect to mass fingerprint fragmentation.

NMR Spectra: Two types of NMR spectra were acquired (CESAMO facilities). A ${ }^{1} \mathrm{H}$ NMR spectrum of Mulsum wine $(0.5 \mathrm{~mL})$ was recorded at $400.13 \mathrm{MHz}$ using a pulse sequence standard with water presaturation and the lock was ensured by the presence of $D_{2} \mathrm{O}$ in a capillary. $\mathrm{A}{ }^{13} \mathrm{C}$ CPMAS spectrum of the residue $3(150 \mathrm{mg}$ of powder) was recorded using a standard CPMAS pulse sequence at $100.6 \mathrm{MHz}$, with a rotation speed of $8 \mathrm{kHz}$. 


\section{Results}

\section{Analytical strategy}

The main concern was to distinguish organic contaminants from the specific rest giving information about the use or even the re-use of the containers. Since it is commonly accepted that the form induces the function and as the amphorae selected in the present work were intended to contain mainly wine, at least for a first use, tracking grape/wine biomarkers, such as tartaric, malic, syringic, citric, p-coumaric and fumaric acids was the main focus $[3,4,6]$. For this purpose, analyses were firstly carried out on the home-made sherd rinsed with distilled water (1-C), or imbibed with solution A (1-A) or with wine (1-W) for testing different approaches. Ceramic samples were weighed before and after soaking and its subsequent drying to have an idea of the quantity of organic matter embedded in the pores. $2612 \mathrm{mg}$ of dried ceramic was imbibed with solution $\mathrm{A}$, and after an imbibition of 3 days and a drying of 1 day in an oven, the sherd reached a weigh of $2616 \mathrm{mg}$, corresponding to $4 \mathrm{mg}$ of solution A absorbed. The $3529 \mathrm{mg}$ sherd reached a weight of $3626 \mathrm{mg}$ after the same treatment with wine, corresponding to a wine absorption of $97 \mathrm{mg}$. $1 \mathrm{~g}$ of each crushed ce- ramic was extracted using the protocol of Pecci et al optimized for wine organic acids [6], and the resultant pellet was taken back for silylation before the GC-MS analysis. The previous imbibition performed with the five reference acids permits both their assignment and their identification in more complex mixtures such as wine, showing that the protocol of extraction used was adapted to the defined objective. (Figure 1) displays the chromatograms obtained for the blank (bottom) compared to sample 1 imbibed with a model solution (middle) or with wine (up). Firstly, this comparison evidences contaminants: beyond the ubiquitous presence of palmitic and stearic acids often attributed to their presence on hands, the detection of syringic acid-commonly used as a biomarker of wine - in the blank was unexpected but can suggest its presence in the clay used for the preparation of the ceramic. Consequently, this acid has not been considered anymore as a wine biomarker in the present study. On the other hand, the different acids sought were identified, along with three others, fumaric, vanillic and lactic acids. If the latter is undoubtedly a biomarker of the fermentation process, fumaric acid is known to be a regulating agent in the malolactic fermentation. For vanillic acid, its presence may have various origins:

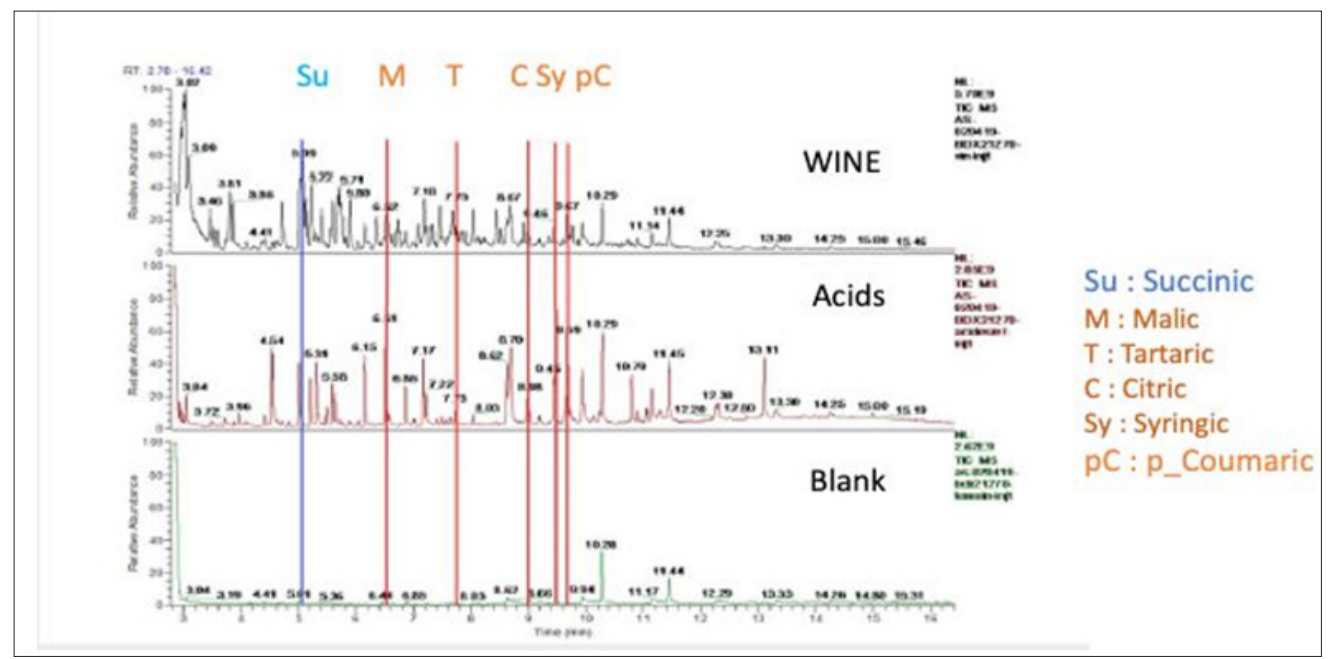

Figure 1: Annotated gas chromatogram (total ion current display, relative abundance against retention times) for ceramic 1 rinsed with distillated water (blank), imbibed with a solution of reference organic acids (acids) or a wine "mulsum" of the "mas des tourelles".

a. Grapes and wines contain at least seven benzoic acids including vanillic acid [10], whose concentrations vary depending on factors such as vine variety, winemaking process, maturity of the grapes [15].

b. A degradation product of anthocyanins during winemaking due to the action of wine lactic acid bacteria, O. Oeni [16].

c. The thermochemolysis of lignin, especially from guaicyl unit, for wine aged in barrels [17].

d. A pyrolytic marker of procyanidins [9].

On the other hand, $2 \mathrm{mg}$ of crushed ceramics 1 and 2 imbibed with wine were directly analyzed by Py-GCMS after methylation with TMAH. The pyrogram profiles obtained were similar for every ceramic imbibed. (Table 2) reports on the relevant compounds with respect to wine detected using this strategy: two organic acids were detected, succinic and fumaric acid, and other characteristic markers of wine that were not observed using the extraction procedure, directed at extracting mainly organic acids. We notice the presence of glycerol markers (2 propanol 1,3 methoxy, and glyceraldehyde dimethyl ether), glycerol being the most abundant constituent of wine after ethanol and water, and also a marker of alcoholic fermentation [10]. Proline was the sole amino acid detected owing to its abundancy in wine, about 30 to $85 \%$ of the total amino acid content [18]. It is usually explained by its specific chemical struc- 
ture (secondary amine) which is not metabolized by yeast during the alcoholic fermentation. Sugars, such as glucose and its oxidized gluconolactone are also detected and probably reflect the addition of honey to wine, as mentioned on the label (5\%). Lastly, 3,4,5-trimethoxy- benzoic acid, methyl ester was identified; it has been previously described as a degradation product of galloylated polyphenols under pyrolysis, and its presence is expected mainly in red wine [9].

Table 2: Compounds identified from sample 1W (homemade ceramic imbibed with wine) or 2W (amphora from Gourgé imbibed with wine) using Py-GCMS and their potential provenience. Source: RT-Retention Time.

\begin{tabular}{|c|c|c|c|c|}
\hline RT (min) & Compound & $\mathbf{1 W}$ & $\mathbf{2 W}$ & Source \\
\hline 1.73 & Glycerol & + & + & Fermentation \\
\hline 2.8 & Glyceraldehyde & + & + & Fermentation \\
\hline 6.46 & Succinic acid derivative & + & + & Fermentation \\
\hline 6.99 & Succinic acid derivative & + & + & Fermentation \\
\hline 7.19 & Fumaric acid derivative & + & + & Fermentation \\
\hline 8.23 & Fumaric acid derivative & & + & Grape \\
\hline 11.18 & d-Proline derivative & + & Honey \\
\hline 11.5 & d-Glucopyranose & & Grape \\
\hline 11,0 & D- $(+)$-Gluconic acid $\delta$-lactone & + & + & Honey \\
\hline 13,4 & Sugar derivative & + & + & Honey \\
\hline 14,09 & Sugar derivative & + & + & Honey \\
\hline 14,42 & Sugar derivative & + & + & Grape \\
\hline 15,83 & D- $(+)$-Gluconic acid $\delta$-lactone & & + & Grape \\
\hline 18,60 & Benzoic acid & + & + & + \\
\hline
\end{tabular}

In order to confirm the presence and/or source attribution of all the compounds detected by py-GCMS, a proton NMR spectrum of the wine used was recorded. (Figure 2) displays this spectrum. It was acquired under water presaturation to visualize the signals of relevant compounds (water represents about $87 \%$ of wine). As expected, the spectrum is dominated by the two resonances of ethanol (compound 7 in the spectrum) (13\% alcoholic degree is indicated on the label of the mulsum). Other resonances of relative intensity are observed between 3 and $4 \mathrm{ppm}$ and should be assigned to several compounds related to wine such as glucose (1), galactose (2), fructose (8), glycerol (9), or even the proline amino acid (4). The anomeric protons of glucose 1 (d, 5.83ppm, ${ }^{3} \mathrm{~J} 3.5 \mathrm{~Hz}$ ) and galactose $2\left(\mathrm{~d}, 4.60 \mathrm{ppm},{ }^{3} \mathrm{~J} 8.0 \mathrm{~Hz}\right)$, standing out from those in the $3-4$ ppm range, are noteworthy by their chemical shifts and coupling constant values. The tartaric 3 (s, 4.82ppm), succinic 6 (s, $2,6 \mathrm{ppm})$ and lactic $5\left(\mathrm{~d}, 1,35 \mathrm{ppm},{ }^{3} \mathrm{~J} 6.5 \mathrm{ppm}\right.$, coupled to those at $4.2 \mathrm{ppm}$ ) acids are also observable in the spectrum. Finally, the presence of coupled resonances at 1.97 and $2.3 \mathrm{ppm}$ can be assigned to the protons $\beta$ and $\gamma$ of proline 4 , and the signals around $7 \mathrm{ppm}$ to aromatic protons of polyphenols, mainly of the procyanidin family.

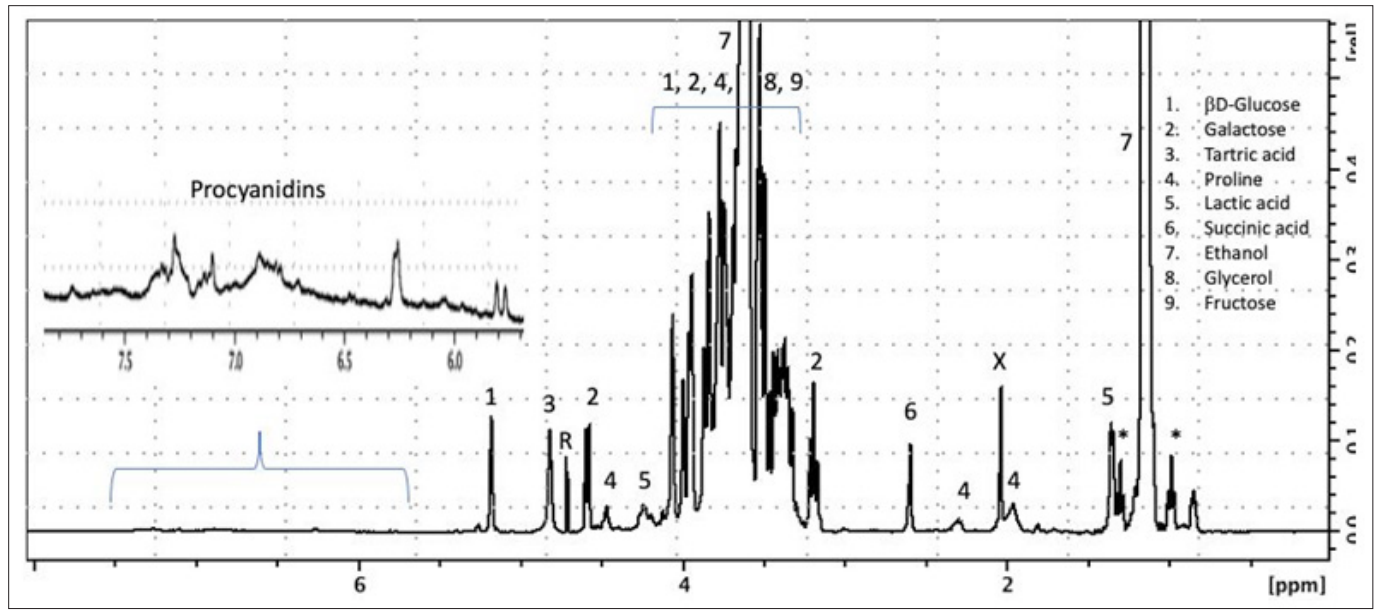

Figure 2: ${ }^{1} \mathrm{H}$ NMR spectrum of mulsum wine, and resonances assignment. Source: R-Residual water, X- Impurity (aceton?), ${ }^{* 13} \mathrm{C}$ satellites from the $\mathrm{CH}_{3}$ resonance of ethanol. 


\section{Application to an archaeological sample}

The analysis of residue 3 collected in an intact Dressel $1 \mathrm{~A}$ amphora (ST41.296) found in well 41 of the Ermitage hill fort in Agen [13] was performed using the two protocols: extraction/silylation on $1 \mathrm{~g}$ and methylation/pyrolysis upon $2 \mathrm{mg}$ of the residue followed by GCMS analysis. The chromatogram (left) and pyrogram (right) profiles recorded for the two protocols are displayed in (Figure 3), and the different compounds found are reported in (Table 3) for GC-MS analysis of the extract and (Table 4) for Py-GCMS performed directly on the residue. The compounds observed whatever the protocol used appear in bold in the two tables (6 in total). Firstly, the predominance of four diterpenic acids of the abietic series, is apparent whatever the protocol used. This diterpene family is known to come from Pinus $s p$. which has traditionally been used for coating the inner side of amphorae since Antiquity $[19,20]$. The observation of succinic acid, known as a biomarker of the alcoholic fermentation, in both pyrograms and chromatograms of the residue supports the use of this type of amphora for wine transport and/ or conservation. The last common compound observed with both approaches is vanillic acid or its decarboxylated derivative trimethoxybenzene, and its possible origins were discussed previously (vide supra). However, hypotheses (iii) and (iv) cannot be retained as its presence in an amphora excludes, a priori, the use of barrels for Italian amphora since wine was made in dolia, and because the vanillic acid was found even in non-pyrolyzed extracts, excluding the degradation due to pyrolysis. This compound has already been observed in archaeological wine and can thus be considered as a wine and grape biomarker [21,22]. However, the absence of the other benzoic acids normally present in wine or grape raises questions. Some compounds were exclusively found in the extract treated by GC-MS: Oxalic acid, commonly found in wine, like benzoic acid and its derivatives, is attributed to degradation products of polyphenols [16]; the ubiquitous palmitic and stearic fatty acids and their derivative azelaic acid (produced by the oxidation of unsaturated palmitic C18:1 w9) were also observed [23].

Table 3: Compounds identified from the extract after GC-MS analysis, with their potential sources of sample 3. Source: FA: Fatty Acid.

\begin{tabular}{|c|c|c|}
\hline RT (min) & Compound & Origine \\
\hline 3,45 & Oxalic acid & Wine \\
\hline 4,39 & Benzoic acid & Grape/Wine \\
\hline 5,02 & Succinic acid & Wine \\
\hline 8,05 & Octanedioic acid & FA \\
\hline 8,54 & Vanillic acid & Wine \\
\hline 8,74 & Azelaic acid & FA \\
\hline 10,31 & Palmitic acid & FA \\
\hline 11,47 & Stearic acid & FA \\
\hline 12,18 & Tetradehydrodehydroabietate derivative & Resin \\
\hline 12,33 & Tetradehydroabietic acid derivative & Resin \\
\hline 12,85 & Methyl 6-dehydrodehydroabietate & Resin \\
\hline 13,42 & 7-Oxodehydroabietic acid, trimethylsilyl ester & Resin \\
\hline 13,63 & 13-cis-Retinoic acid, trimethylsilyl ester & FA \\
\hline
\end{tabular}

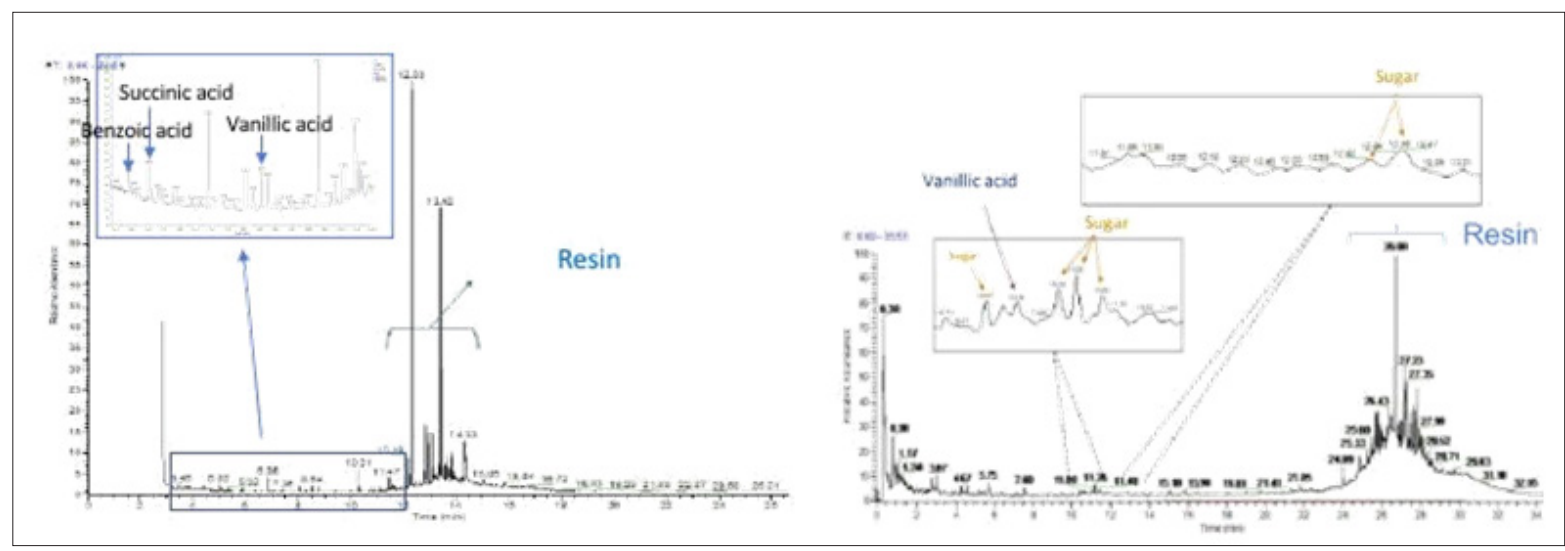

Figure 3: Annotated gas chromatogram of the extract (left) and pyrogram of 1-2mg of sample 3 (right): total ion current against retention time. 
As expected, the pyrogram of the residue offers a wider variety of compounds (Table 4 \& Figure 3). Most of them can be related to wine or resin. Concerning the biomarkers of resin, the presence of seven supplementary isomers compared to the analysis on the extract was noticed (Table 3). These differences can be explained by the protocol of extraction used, which was oriented to extract mainly organic acids, the common protocol used for extracting resinic acids being performed with organic solvents [21]. Nevertheless, all these species are known to be present in pine resin, where the $\mathrm{C}_{20} \mathrm{H}_{28} \mathrm{O}_{2}, \mathrm{C}_{20} \mathrm{H}_{26} \mathrm{O}_{2}, \mathrm{C}_{20} \mathrm{H}_{28} \mathrm{O}_{3}, \mathrm{C}_{20} \mathrm{H}_{26} \mathrm{O}_{3}$ isomers are related to various diagenetic processes of alteration by aromatization and/or oxidation, and the origin of this chemical transformation seems difficult to attribute to human activity (such as heating) or to natural decay in the sedimentary matrix [24]. These different resinic acids corresponded to the main resonances observed in the solid-state NMR spectrum of the residue (Figure 4). The resonances observed are as follow: the aliphatic (15-50ppm), aromatic (120-150ppm) and carboxylic regions (170-190ppm); oxidation effect are also perceptible through the resonances 7 DH-CO centered at 156ppm and 7,15 $\mathrm{DH}-\mathrm{OH}$ at 80ppm [25]. All the chemical structures of these resinic derivatives are reported on (Figure 5). This result confirms the presence of different chemical species observed using Py-GCMS and shows, as expected, that resin is the predominant component of the residue.

Table 4: Compounds identified in residue 3, using py-GCMS after methylation with TMAH and their supposed source. Source: ? are probably pollutant compounds. PC: Procyanidins. Are reported herein the main peaks identified.

\begin{tabular}{|c|c|c|}
\hline RT (min) & Compound & Origin \\
\hline 3,07 & Benzene, 1,3-diethyl- & $?$ \\
\hline 3,94 & Succinic acid derivative & Grape? \\
\hline 4,34 & Benzoic acid & Grape/Wine \\
\hline 5,38 & Diacid & $?$ \\
\hline 6,16 & Glutaric acid derivative & Grape/Honey \\
\hline 7,01 & p-Cumic aldehyde & Myrrhe? \\
\hline 9,56 & 1,2-Dimethoxy-4- ethylbenzene & PC \\
\hline 9,81 & 3-Methoxy Benzoic acid & $\mathrm{PC}$ \\
\hline 10,13 & 4-(1-Methylethyl)-Benzoic acid & Myrrh \\
\hline 10,47 & Glucose derivative & Honey \\
\hline 10,62 & 2-Methoxy-4-(1-propenyl)-Phenol, ethyl-gaïacol & Wine \\
\hline 10,74 & Trimethoxy benzene & Wine? \\
\hline 11,09 & D-Glucose derivative & Honey \\
\hline 16,51 & 1,2-Dimethoxy-4-(3-methoxypropyl)benzene & Degraded PC? \\
\hline 25,60 & Resinic acid derivative $\mathrm{C}_{2} \mathrm{OH}_{3} \mathrm{OO}_{2}$ & Resin \\
\hline 25,77 & Resinic acid derivative $\mathrm{C}_{2} \mathrm{OH}_{3} \mathrm{OO}_{2}$ & Resin \\
\hline 25,84 & Resinic acid derivative $\mathrm{C}_{2} \mathrm{OH}_{39} \mathrm{O}_{2}$ & Resin \\
\hline 25,98 & Resinic acid derivative $\mathrm{C}_{2} \mathrm{OH}_{3} 0 \mathrm{O}_{2}$ & Resin \\
\hline 26,26 & Resinic acid derivative $\mathrm{C}_{2} \mathrm{OH}_{3} \mathrm{OO}_{2}$ & Resin \\
\hline 26,80 & Dehydroabietic acid methyl ester $\mathrm{C}_{2} \mathrm{OH}_{28} \mathrm{O}_{2}$ & Resin \\
\hline 27,23 & Resinic acid $\mathrm{C}_{2} \mathrm{OH}_{26} \mathrm{O}_{2}$ & Resin \\
\hline 27,35 & 7-Methoxy-tetradehydroabietic acid, $\mathrm{C}_{21} \mathrm{H}_{28} \mathrm{O}_{3}$ & Resin \\
\hline 27,68 & 15-Hydroxydehydroabietic acid, $\mathrm{C}_{2} \mathrm{OH}_{28} \mathrm{O}_{3}$ & Resin \\
\hline 27,90 & 7-Oxodehydroabietic acid, methyl ester $\mathrm{C}_{2} \mathrm{OH}_{26} \mathrm{O}_{3}$ & Resin \\
\hline 27,99 & 7,15-Dimethoxytetradehydroabietic acid, $\mathrm{C}_{22} \mathrm{H}_{30} \mathrm{O}_{4}$ & Resin \\
\hline
\end{tabular}




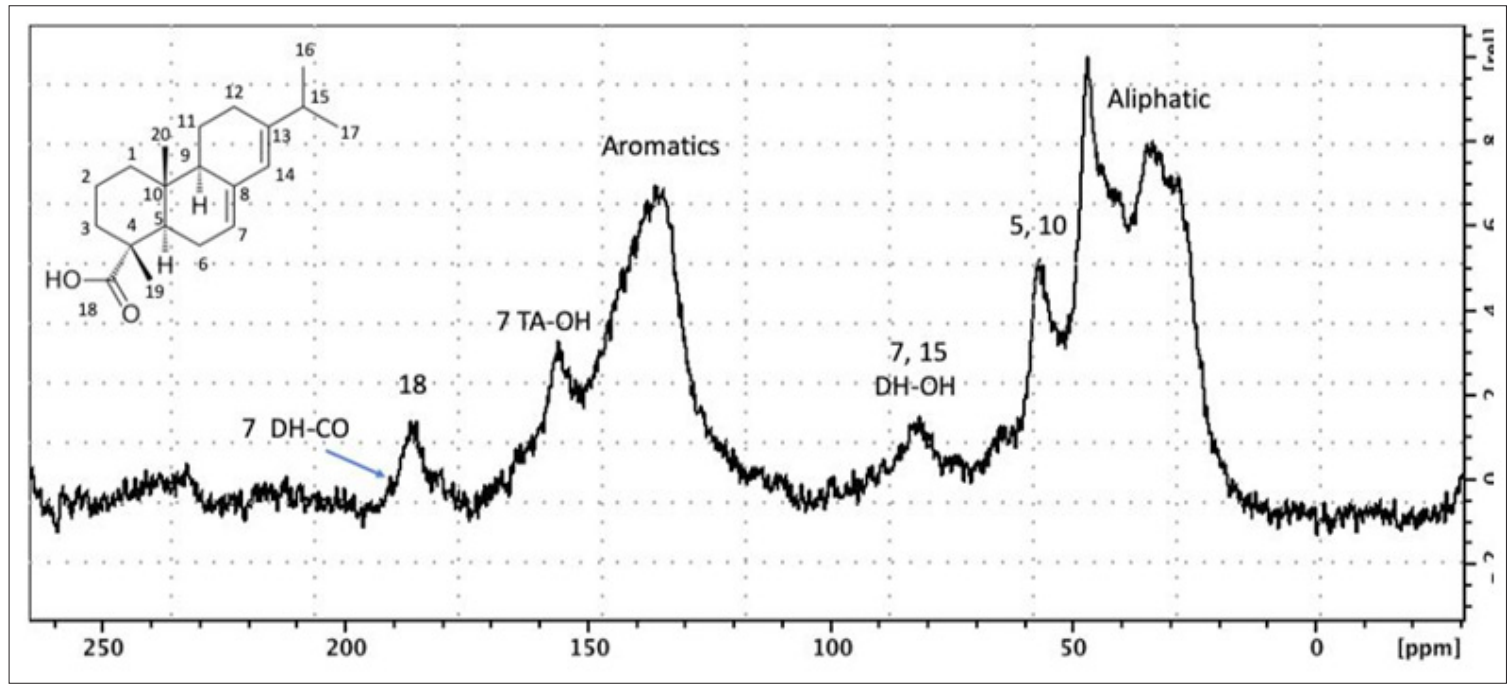

Figure 4: Solid-State ${ }^{13} \mathrm{C}$ NMR spectrum of residue 3 (CPMAS experiment). Assignments are done with respect to resin derivatives found in the Py-GCMS analysis. The different structures identified are displayed in Figure 5 (7 DH-CO; 7 TA-OH; 7,15 DH-OH).

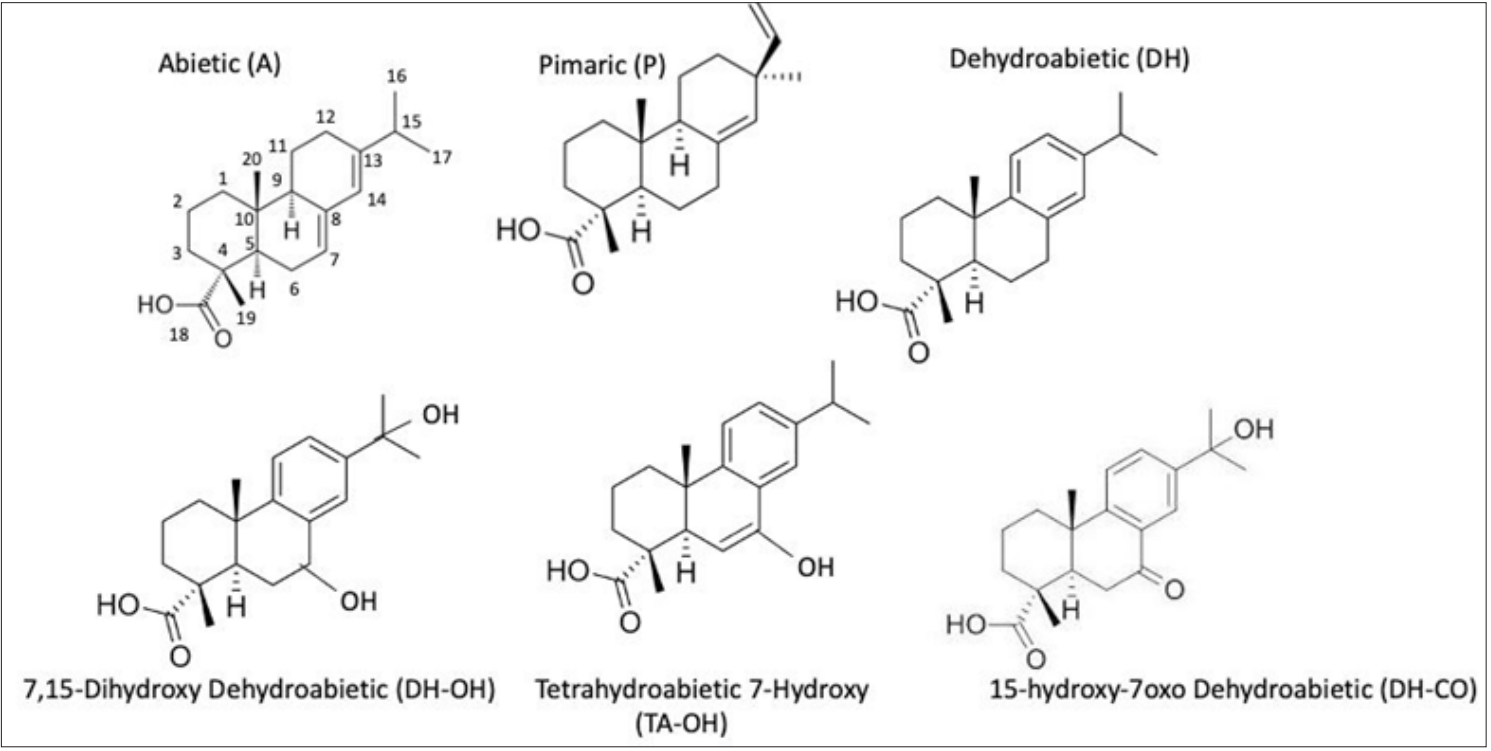

Figure 5: Chemical structures of the resinic acids encountered.

Contrarily to NMR, and fortunately, Py-GCMS also permits the detection of minor but decisive components. Sugars and derivatives (such as glucuronic acid) were identified. They should reflect the addition of honey, a common practice to obtain a Mulsum $(20, \mathrm{NH}$ XIV, 85). However, their presence can also reflect the use of sundried grapes (that permits the concentration of sugars) to obtain a Passum (20, NH XIV, 81). The detection of di/trimethoxybenzenoids in the pyrogram was of interest: their presence can reflect thermochemolysis products of procyanidins [9] whose abundance provides information on the colour of the grape (red grapes are richer in tannins than white, 10). Finally, the presence of p-cumic aldehyde is noteworthy: it is responsible for the odor of cumin, and is known to be present in myrrh. Could its detection be explained by the addition of myrrh to this wine? Since herbs and spices were frequently added to wine, as explained by Pline the Oldest in his Naturalis Historia dedicated to wine and vine (20, NH, XIV, 134), this attribution may be plausible.

\section{Discussion}

If adapting an analytic protocol enables to better elucidate specific compounds, it is fortuitous to find an unexpected compound. As example, in amphorae forms known to have contained wine, most researchers focused on finding wine biomarkers such as organic acids and adapted an extraction procedure according to this purpose. To date, there are three of them, the approach proposed by McGovern et al. [5,6] and Garnier [8] with the same objective, 
detecting L-tartaric acid or its salt specific to grapes and thus wine and, since the analytical procedure permits it, other organic acids responsible for wine acidity such as malic, fumaric, succinic and lactic acids. Herein, another analytical strategy is proposed : a technique developed in the 1960s, pyrolysis coupled with GCMS - PyGCMS- was implemented. It offers the possibility to analyze organic macromolecules of low volatility and is currently utilized in the vast domain of archaeological sciences for characterizing organic paint binders [26] or natural and synthetic resins [27]. In the present work, the Py-GCMS is directly applied on sherds without any prior extraction before to obtain a molecular print of the sherd content. This approach has been previously used twice: Oudemans and Boon [28] applied Py-GCMS on a sherd and detected both aromatic and aliphatic compounds, and Kaal and collaborators [29] explored this method on a series of potsherds and provides a rapid molecular screening of the organic matters embedded in the pottery matrix. In those two examples, a methylation reaction was conducted using a protocol adapted from Challinor [14], as this step increases the compounds volatility for further GCMS detection.

As shown in the present work, this approach evidences the presence of compounds that were not detected in the extract, the chosen method permitting to extract mainly the organic acid fraction. If the use of Py-GCMS does not allow observation of all ten acids observed in the extract (only three of them were observed: fumaric, succinic and benzoic acids; Table 2), some other compounds of interest were detected. Sugars are identified in accordance with the addition of honey as indicated on the Mulsum bottle, as well as an amino acid known to be commonly found in wine. As proof of their presence in Mulsum, all these compounds were detected by ${ }^{1} \mathrm{H}-\mathrm{NMR}$. This approach was applied to an archaeological residue sampled from an amphora. Four acids were identified in the extract (oxalic, benzoic, succinic, vanillic acids, Table 3), as well as resinic acids, whose presence is in accordance with a pretreatment of the amphora with resin and content such as wine. In addition, other components of interest were also observed on the pyrogram, possibly providing information about the amphora content or even the winemaking process. In that regard, the presence of sugars is remarkable since it suggests the addition of honey or/and the use of sun-dried grapes. The presence of tannins (procyanidins) derivatives is equally noticeable, as it indicates the red color of wine - their presence being at least 10 to 50-fold larger than in white wine [10]. The combination of the two methods (extraction followed by GCMS, and Py-GCMS) allows the identification of a lot of different components. It will be applied in the future in amphorae found in the Picton territory (western center of Gaul) where local workshops were discovered [12]. Picton potters notably reproduced different forms of amphorae (Dressel 2/4 or Gauloise 4 and 5), and the chemical analysis of the residues found in those vessels discovered in consumption sites will ascertain to what end they were manufactured. Indeed, the direct use of Py-GCMS on a ceramic fragment or a solid residue (1-2mg) can give an idea of the nature of the compounds present and thus direct their extraction for a more detailed analysis.

\section{Acknowledgment}

This article is part of the project ITI-Vin financed by the Région Nouvelle Aquitaine (CRNA ITI-Vin). NMR and Mass Spectrometry analyses were performed at the Centre d'Etude Structural et d'Analyse des Molécules Organiques (CESAMO), ISM, Université de Bordeaux, Département Sciences et Technologie, the authors thank the CESAMO team, and especially Cybille Rossy, for their/her help and Nathan McClenaghan for the English.

\section{Contributions}

The paper was written through contributions of all authors. All authors gave approval to the final version of the manuscript. CSR and CF performed most of the experiments as part of their university cursus (Master and PhD, for CSR and CF, respectively). NC and FV participated to the choice of archaeological samples and discussion, SV manages the ITI-Vin project, IP conceptualizes the experiments with the help of CA and wrote the paper, CN represents a scientific consortium created to affirm the collaborative and open nature of the creation and dissemination of knowledge, under the control of the academic community, in which all the authors identified themselves.

\section{References}

1. Nigra BT, Faull KF, Barnard H (2015) Analytical chemistry in archaeological research. Anal Chem 87(1): 3-18.

2. McGovern PE, Hall GR (2016) Charting a future course for organic residue analysis in archaeology. J Archaeol Method Theory 23(2): 592622.

3. Michel RH, McGovern PE, Badler VR (1993) The first wine \& beer, chemical detection of ancient fermented beverages. Anal Chem 65(8): 408-413.

4. Jerkovic I, Marijanovic Z, Gugic M, Roje M (2011) Chemical profile of the organic residue from ancient amphora found in the Adriatic sea determined by direct GC and GC-MS analysis. Molecules 16(9): 79367948.

5. McGovern PE, Luley BP, Rovira N, Mirzoian A, Callahan MP, et al. (2013) Beginning of viniculture in France. Proc Natl Acad Sci USA 110(25): 10147-10152.

6. Pecci A, Giogi G, Salvini L, Cau Ontiveros MA (2013) Identifying wine markers in ceramics and plasters using gas chromatographyemass spectrometry. Experimental and archaeological materials. J Arch Sci 40: 109-115.

7. Bonaduce I, Ribechini E, Modugno F, Colombini MP (2016) Analytical approaches based on gas chromatography mass spectrometry (GC/MS) to study organic materials in artworks and archaeological objects. Top Cur Chem 374: 1-37.

8. Garnier N, Valamoti SM (2016) Prehistoric wine-making at Dikili Tash (Northern Greece): Integrating residue analysis and archaeobotany. J Arch Sci 74: 195-206.

9. Garnier N, Richardin P, Cheynier V, Regert M (2003) Characterization of thermally assisted hydrolysis and methylation products of polyphenols from modern and archaeological vine derivatives using gas chromatography-mass spectrometry. Anal Chim Acta 493: 137-157.

10. Ribéreau Gayon P, Dubourdieu D, Glories Y, Maujean A (2017) Traité d'Oenologie. In: 1-7e, Europe, pp. 1-355. 
11. Gourgé BD (2008) Le Bourgest: Excavation of a secondary agglomeration of pictons. INRAP: Poitiers, France.

12. Durquety M, Lemaître S, Guitton D (2012) Production and consumption of regional amphorae in Picton territory. In: SFECAG, Europe, pp. 395406.

13. Verdin Fl, Berthault FR, Sanchez C (2013) Well 41 of the oppidum of the Hermitage of Agen (Lot-et-Garonne): overview of the amphoric facies and questions of chronology. In: Olmer F (Ed.), (2007) Routes des vins romains en Gaule IIIe-Ier centuries BC Facies confrontation, Proceedings of the European conference organized by UMR 5140 of the CNRS Lattes, MAM Hors-série 5, pp. 125-138.

14. Challinor JM (2001) Review: The development and applications of thermally assisted hydrolysis and methylation reactions. J Anal Appl Pyrolysis 61(1-2): 3-34.

15. Tian RR, Pan QH, Zhan JC, Li JM, Wan SB, et al. (2009) Comparison of phenolic acids and flavan-3-ols during wine fermentation of grapes with different harvest times. Molecules 14(2): 827-838.

16. Devi A, Konerira Aiyappaa AA, Waterhouse AL (2020) Adsorption and biotransformation of anthocyanin glucosides and quercetin glycosides by Oenococcus oeni and Lactobacillus plantarum in model wine solution. J Sci Food Agric 100(5): 2110-2120.

17. Vivas N, Pianet I, Bourgeois G, Vitry C, Servens C, et al. (1998) Characterization of heartwood lignin fractions from Quercus robur $L$. and Quercus petraea (Matt) Liebl., the main oak species used for barrel making. Am J Enol Vitic 49: 49-55.

18. Lehtonen $P$ (1996) Determination of amines and amino acids in wine-a review. Am J Enol Vitic 47(2): 126-133.

19. Columella (1988) Agriculture. In: Book-XII, J André, Europe, pp. 1-238.
20. John Bostock (1958) The Natural history of the fruit trees. Pliny the Elder, Natural History, J André, Europe.

21. Cau Ontiveros MA, Martinez Farreras V, Pecci A, Mas Florit C, Fantuzzi $\mathrm{L}$ (2018) Archaeometric analysis for provenance and content of roman amphorae from the site of Sa Mesquida (Mallorca, Spain). Mediterr Archaeol Ar 18(2): 87-105.

22. Fujii H, Mazzitelli JB, Adilbekov D, Olmer F, Mathe C, et al. (2019) FT-IR and GC-MS analyses of dressel $1 \mathrm{~A}$ amphorae from the grand congloué 2 wreck. J Archaeo Sci: Reports 28: 102007.

23. Evershed RP, Mottram HR, Dudd SN, Charters S, Stott AW, et al. (1997) New criteria for the identification of animal fats preserved in archaeological pottery. Naturwissenschaften 84: 402-406.

24. Regert M (2004) Investigating the history of prehistoric glues by gas chromatography-mass spectrometry. J Sep Sci 27(3): 244-254.

25. Lambert JB, Poinar GO (2002) Amber: The organic gemstone. Acc Chem Res 35(8): 628-636.

26. Bonaduce I, Andreotti A (2009) Py-GC:MS of organic paint binders. In: Colombini MP, Modugno F (Eds.), Wiley, USA, pp. 1-483.

27. Scalarone D, Chiantore O (2009) Py-GC/MS of natural and synthetic Resins. In: Maria Perla Colombini Francesca Modugno (Ed), Wiley, USA, pp. 1-483.

28. Oudemans TFM, Boon JJ (1991) Molecular archaeology: Analysis of charred (food) remains from prehistoric pottery by pyrolysis-gas chromatography/mass spectrometry. J Anal Appl Pyrolysis 20: 197-227.

29. Kaal J, Lantes Suarez O, Martinez Cortizas A, Prieto B (2014) How useful is pyrolysis-GC/MS for the assessment of molecular properties of organic matter in archaeological pottery matrix? An exploratory case study from North-West Spain. Archaeometry 56(S1): 187-207.

For possible submissions Click below: 